\title{
Economics of Processing of Different Tapioca Based Products in Salem District of Tamil Nadu, India
}

\author{
V. Kathiravan ${ }^{1 *}$, S. Saranya ${ }^{2}$, K. Sangli Vikram Kumar ${ }^{3}$ and D. David Rajasekar ${ }^{2}$ \\ ${ }^{1}$ Agricultural Economics, The Indian Agriculture College, Radhapuram, \\ Tirunelveli - 627 111, Tamil Nadu, India \\ ${ }^{2}$ Department of Agricultural Economics, AC \& RI, Madurai - 625 104, Tamil Nadu, India \\ ${ }^{3}$ Animal Husbandry, The Indian Agriculture College, Radhapuram, \\ Tirunelveli - 627 111, \\ Tamil Nadu, India \\ *Corresponding author
}

A B S T R A C T

\begin{tabular}{|c|c|}
\hline Keywords & $n$ processing of tapioca into sta \\
\hline $\begin{array}{l}\text { Tapioca, Cost, } \\
\text { Returns, Processing } \\
\text { units, Salem, Tamil } \\
\text { Nadu. }\end{array}$ & $\begin{array}{l}\text { units are engaged tapioca processing and also under the membership of sago serve } \\
\text { in Salem district. Present study aims to quantify cost and returns of tapioca } \\
\text { processing industry in different scale of production and also identified the }\end{array}$ \\
\hline Artic & lakh and it increasing across the scale of production and it was 120.11 lakh for \\
\hline $\begin{array}{l}\text { Accepted: } \\
\text { 15 September } 2017 \\
\text { Available Online: } \\
10 \text { November } 2017\end{array}$ & $\begin{array}{l}\text { largest firm. The Major constraints faced by processing firm were unavailability } \\
\text { quality raw material, high cost of electricity and frequent power cuts in the study } \\
\text { area. This study suggests that government should take necessary iaction to to guard } 13 \\
\text { the investors of tapioca processing industry. }\end{array}$ \\
\hline
\end{tabular}

\section{Introduction}

Tapioca (Manihot esculenta Crantz) was introduced in India during the later part of the 18th Century. Tamil Nadu stands first in respect of processing of tapioca into starch and sago. In India, the cultivation of cassava is mainly done in Kerala, Tamil Nadu, Andhra Pradesh, Nagaland, Meghalaya, Assam, etc. Tamil Nadu stands first both in area and production followed by Kerala and Andhra Pradesh. As per the second advanced estimates for the period 2012-13, the total area under tapioca in India is 216.66 thousand thousand metric tonnes. In Tamil Nadu is 109.56 thousand hectares and the production is about 4205.82 thousand metric tonnes (Vigneshwara Varmudy, 2014).

Sago was produced first in Salem of Tamil Nadu state. About 50 years ago in 1943-44, sago production started on a cottage scale basis in India. Tapioca root is the basic raw material for sago and starch. Generally about 30 to 35 percent starch content will be 
there in Indian tapioca root. The District offers good raw material, cheap labour and good sunshine for a longer period of the day throughout the year; helping manufacturers to produce more tapioca finished products eg. sago and starch and therefore the District of Salem is known as the land of Sago, even in the international forums. In and around Salem the yield of tapioca is about 25-30 t/ha, highest in the World. National average is 19 t/ha and World average production stands at 10 t/ha (Sagoserve, Salem).

In 1981, Salem Starch and Sago Manufacturers Service Industrial Cooperative Society Ltd (popularly called as SAGOSERVE) was established to promote the growth of sago industries. Nearly 80 percent of the national demand for Sago and Starch is being met by the Sagoserve.

Tamil Nadu stands first in processing of tapioca in the starch and sago meeting 80 percent of the demand at the national level in food, non - food sectors. It is a very nutritious product as it contains Carbohydrates and appreciable amount of Calcium and VitaminC (FAO). More than 400-500 sago-producing units are located in Tamil Nadu alone.

Although sago production is confined to Tamil Nadu and Andhra Pradesh, it is consumed throughout the country. Maximum volume of sago is consumed in Maharashtra for the preparation of khichdi, upma, bonda, payasam, etc. In West Bengal, sago is used as a baby food. In other parts, it is used in preparing payasam and wafers. The demand for sago is generally more during festival seasons (Vigneshwara Varmudy, 2014).

The present study has examined the following objectives:

To workout the capital investment requirement for different tapioca based products across different scale of production in the study area;

To examine the economics of processing of different tapioca based product across different scale of production in the study area;

To develop long run average cost curve and to examine the optimum scale of production in tapioca processing industry in the study area; and

To identify the constraints involved in the processing of tapioca and to suggest appropriate policy measure to improve the production of tapioca based products in the study area.

\section{Materials and Methods}

Salem district was purposively selected as the universe of the study, since Salem district stands first in tapioca processing with a large number of tapioca processing units. About 387 tapioca processing units are engaged tapioca processing and also under the membership of sago serve in Salem district.

All the 387 units were arranged in the ascending order based on their processing capacity and categorized into five groups with the capacity of 500-800 tonnes, 801-1100 tonnes, 1101-1400 tonnes, 1401-1700 tonnes and above 1701 tonnes. Then one processing unit from each group was selected at random, thus constituting six processing units study the processing and financial aspect of tapioca based products.

\section{Tools of analysis}

The cost and returns in the selected processing units were estimated. The total processing cost was worked by summing annual share of capital, variable cost and fixed cost. The gross return of a unit was estimated by adding the revenues from the 
sale of the main and bi-products. The net return was derived by deducting total costs from total returns. Percentage and average analysis was used in analysing the general details of the processing units, investment pattern, cost and returns.

\section{Results and Discussion}

\section{Different stages of tapioca processing}

\section{Grading and washing}

The tubers after harvesting were graded using point scale such as 10, 20, 25 and 30 etc. After grading, tapioca tubers were sending to the processing unit. Then, tapioca tubers were washed using water for processing.

\section{Peeling and crushing}

The washed tubers are peeled and crushed with water in to a milky form.

\section{Filtering}

Milky form of tapioca tubers was filtered through 80, 120 and $250 \mathrm{~mm}$ nylon mesh. Then, milk was run through a pipe which is about $150 \mathrm{ft}$ length and $20 \mathrm{ft}$ breadth.

\section{Settling}

Milky form was separated in to starch and fibre using tub. The starch alone settled in the first tub and fibre stored in another tub. Fibers were sold to as a cattle feed.

\section{Drying}

Wet starch should be dried in a drying yard and dried starch can be packed as a bag of 90 kilogram starch.

\section{Sizing}

Only for sago preparation: From the wet starch, by using sizing machineries starch was prepared as a granule. It is roasted by quick ovens and it is dried in the drying yard and polished using a machines. Then, it will be packed as a bag of 90 kilogram sago.

\section{Average production per processing unit}

Average production per processing unit furnished in the Table 1. It could be observed that sago was main product from processing, constituting 79.15 percent of the tapioca based products and the rest was starch with the proportion of 20.85 percent.

\section{Cost and returns of tapioca processing units}

\section{Capital investment}

Capital investment across different processing units is furnished in the Table 2. The total capital investment across different scale of production is 329 lakh rupees to 500.50 lakh rupees. The total capital investment the land constituted around 33 to 37 percent. Building and permanent structure ranged from 24 percent to 33.5 percent. The value of machinery, tools and equipment constituted in proportion of total capital investment ranged from 30 to 39 percent.

\section{Variable cost incurred by tapioca processing}

The details on variable cost incurred by the tapioca processing units in different scale of production are given in Table 3. As regards total variable cost for the smallest firm were 369 lakh rupees while it was 845 lakh rupees for the largest firm. The major component in the variable cost was tapioca roots with the share ranging from 48.51 percent to 65.04 percent and it is shows an increasing trend across the scale of firm. The next major 
component of variable cost was labour cost which varies from 14.37 to 26.88 and it is decreasing pattern across the scale of firm. The next major component was electricity, diesel and firewood which the share ranging from 9.32 to 13.04 percent followed by packing and packaging material and miscellaneous expenditure.

Table.1 Average production per processing unit (tonnes)

\begin{tabular}{|l|l|l|}
\hline Product & Average production per unit in the industry (tonnes) & Percentage to total \\
\hline Sago & 182.418 & 79.15 \\
\hline Starch & 47.97 & 20.85 \\
\hline Total & 230.388 & 100 \\
\hline
\end{tabular}

Table.2 Capital investment of tapioca processing firms under different scale of production (Value in lakh)

\begin{tabular}{|l|l|l|l|l|l|l|}
\hline \multirow{2}{*}{$\begin{array}{l}\text { Sl. } \\
\text { No }\end{array}$} & \multirow{2}{*}{ Capital } & \multicolumn{6}{l|}{ Different scale of production } \\
\cline { 3 - 7 } & & $\mathbf{5 0 0 - 8 0 0}$ & $\mathbf{8 0 0 - 1 1 0 0}$ & $\mathbf{1 1 0 1 - 1 4 0 0}$ & $\mathbf{1 4 0 1 - 1 7 0 0}$ & Above 1701 \\
\hline \multirow{2}{*}{1} & \multirow{2}{*}{ Land } & 120.00 & 140.00 & 150.00 & 170.00 & 180.00 \\
& & $(36.47)$ & $(37.43)$ & $(33.41)$ & $(36.13)$ & $(35.96)$ \\
\hline \multirow{2}{*}{2} & Building and permanent & 110.00 & 120.00 & 142.00 & 122.00 & 122.500 \\
& structure & $(33.44)$ & $(32.09)$ & $(31.62)$ & $(25.92)$ & $(24.47)$ \\
\hline \multirow{2}{*}{3} & Machinery, tools and & 99.00 & 114.00 & 157.00 & 178.50 & 198.00 \\
& equipments & $(30.09)$ & $(30.49)$ & $(34.96)$ & $(37.94)$ & $(39.56)$ \\
\hline & \multirow{2}{*}{ Total capital investment } & 329.00 & 374.00 & 449.00 & 470.50 & 500.50 \\
& $(100)$ & $(100)$ & $(100)$ & $(100)$ & $(100)$ \\
\hline
\end{tabular}

Note: Figure in the parentheses is percent to the total.

Table.3 Variable cost incurred by the tapioca processing firms in different scale of production (Rs. in lakh)

\begin{tabular}{|l|l|l|l|l|l|l|}
\hline \multirow{2}{*}{$\begin{array}{l}\text { Sl. } \\
\text { No }\end{array}$} & \multirow{2}{*}{ Particulars } & \multicolumn{6}{l|}{ Different scale of production (tonnes) } \\
\cline { 3 - 7 } & & $\mathbf{5 0 0 - 8 0 0}$ & $\mathbf{8 0 1 - 1 1 0 0}$ & $\mathbf{1 1 0 1 - 1 4 0 0}$ & $\mathbf{1 4 0 1 - 1 7 0 0}$ & Above 1701 \\
\hline \multirow{2}{*}{1} & \multirow{2}{*}{ Quantity of tapioca roots } & 179.2 & 282 & 374.5 & 482.5 & 550 \\
& & $(48.51)$ & $(57.67)$ & $(59.77)$ & $(63.42)$ & $(65.04)$ \\
\hline \multirow{2}{*}{2} & Packing and packaging & 19.88 & 18.4 & 31.2 & 34.0 & 36.72 \\
& material & $(5.38)$ & $(3.76)$ & $(4.98)$ & $(4.47)$ & $(4.34)$ \\
\hline \multirow{2}{*}{3} & Labours & 99.275 & 110.875 & 108.55 & 114.175 & 121.525 \\
& & $(26.88)$ & $(22.67)$ & $(17.32)$ & $(15.01)$ & $(14.37)$ \\
\hline \multirow{2}{*}{4} & \multirow{2}{*}{ Electricity, diesel, firewood } & 48.178 & 51.328 & 71.538 & 75.563 & 78.841 \\
& & $(13.04)$ & $(10.50)$ & $(11.42)$ & $(9.93)$ & $(9.32)$ \\
\hline \multirow{2}{*}{5} & \multirow{2}{*}{ Miscellaneous exp. } & 15.6 & 10.6 & 20.6 & 20.6 & 20.85 \\
& & $(4.22)$ & $(2.17)$ & $(3.29)$ & $(2.71)$ & $(2.47)$ \\
\hline \multirow{2}{*}{6} & Working capital & 362.134 & 473.203 & 606.388 & 726.838 & 807.936 \\
& & $(98.040$ & $(96.77)$ & $(96.77)$ & $(95.54)$ & $(95.54)$ \\
\hline 7 & \multirow{2}{*}{ Interest on working capital } & 7.243 & 15.773 & 20.213 & 33.919 & 37.704 \\
& $(1.96)$ & $(3.23)$ & $(3.23)$ & $(4.46)$ & $(4.46)$ \\
\hline & Total variable cost & 369.376 & 488.977 & 626.601 & 760.757 & 845.640 \\
& & $(100)$ & $(100)$ & $(100)$ & $(100)$ & $(100)$ \\
\hline
\end{tabular}


Note: Figure in the parentheses is percent to the total.

Table.4 Fixed cost of processing firms in different scale of production (Rs in lakh)

\begin{tabular}{|l|l|l|l|l|l|l|}
\hline \multirow{2}{*}{$\begin{array}{l}\text { Sl. } \\
\text { No }\end{array}$} & \multirow{2}{*}{ Particulars } & \multicolumn{6}{|l|}{ Different scale of the production (tonnes) } \\
\cline { 3 - 7 } & & $\mathbf{5 0 0 - 8 0 0}$ & $\mathbf{8 0 1 - 1 1 0 0}$ & $\mathbf{1 1 0 1 - 1 4 0 0}$ & $\mathbf{1 4 0 1 - 1 7 0 0}$ & Above 1701 \\
\hline \multirow{2}{*}{1} & Salary of the & 1.800 & 1.800 & 1.440 & 1.800 & 1.800 \\
& manager & $(8.58)$ & $(7.69)$ & $(5.82)$ & $(6.80)$ & $(6.26)$ \\
\hline \multirow{2}{*}{2} & Repairs and & 2.897 & 3.025 & 3.025 & 4.529 & 3.705 \\
& maintenance & $(13.80)$ & $(12.92)$ & $(12.22)$ & $(17.12)$ & $(12.89)$ \\
\hline \multirow{2}{*}{3} & Duties and taxes & 0.120 & 0.136 & 0.136 & 0.137 & 0.138 \\
& & $(0.57)$ & $(0.58)$ & $(0.55)$ & $(0.52)$ & $(0.47)$ \\
\hline \multirow{2}{*}{4} & Depreciation & 15.147 & 16.947 & 19.147 & 18.147 & 21.247 \\
& & $(72.16)$ & $(72.40)$ & $(77.37)$ & $(68.57)$ & $(73.93)$ \\
\hline \multirow{2}{*}{5} & Rental value of & 1.025 & 1.500 & 1.000 & 1.850 & 1.850 \\
& land & $(4.88)$ & $(6.41)$ & $(4.04)$ & $(6.99)$ & $(6.44)$ \\
\hline & \multirow{2}{*}{ Total fixed cost } & 20.989 & 23.408 & 24.748 & 26.463 & 28.738 \\
& $(100.00)$ & $(100.00)$ & $(100.00)$ & $(100.00)$ & $(100.00)$ \\
\hline
\end{tabular}

Table.5 Total processing cost of tapioca processing firms in different scale of production (Rs. In lakh)

\begin{tabular}{|l|l|l|l|l|l|l|}
\hline \multirow{2}{*}{ Sl.no } & \multirow{2}{*}{ Particulars } & \multicolumn{4}{l|}{ Different scale of production (tonnes) } \\
\cline { 3 - 7 } & & $500-800$ & $801-1100$ & $1101-1400$ & $1401-1700$ & Above 1701 \\
\hline 1 & Total variable cost & 369.376 & 488.976 & 626.601 & 760.757 & 845.640 \\
\hline 2 & Total fixed cost & 20.989 & 23.407 & 24.748 & 26.4628 & 28.738 \\
\hline 3 & Annual share of capital & 8.225 & 9.275 & 11.225 & 11.7625 & 12.5125 \\
\hline 4 & Total processing cost & 398.590 & 521.659 & 662.573 & 798.983 & 886.890 \\
\hline 6 & $\begin{array}{l}\text { Total processing cost of } \\
\text { per kg of product (Rs) }\end{array}$ & 12.3 & 9.65 & 9.08 & 8.44 & 8.21 \\
\hline
\end{tabular}

Table.6 Profit realized in the processing firms in different scale of production (Rs in lakh)

\begin{tabular}{|l|l|l|l|l|l|l|}
\hline \multirow{2}{*}{ Sl.no } & \multirow{2}{*}{ Particulars } & \multicolumn{4}{|c|}{ Different scale of production in tonnes (capacity of selected firms) } \\
\cline { 3 - 7 } & & $\begin{array}{c}500-800 \\
(549)\end{array}$ & $\begin{array}{c}801-1100 \\
(945)\end{array}$ & $\begin{array}{c}1101-1400 \\
(1260)\end{array}$ & $\begin{array}{c}1401-1700 \\
(1575)\end{array}$ & $\begin{array}{c}\text { Above 1701 } \\
(1881)\end{array}$ \\
\hline 1 & Gross return & 415.379 & 570.313 & 732.353 & 891.953 & 1007.001 \\
\hline 2 & Total processing cost & 398.590 & 521.659 & 662.574 & 798.983 & 886.890 \\
\hline 3 & Net return & 16.7892 & 48.6537 & 69.7791 & 92.9705 & 120.1108 \\
\hline 4 & $\begin{array}{l}\text { Profit realized per } \\
\text { Kg of product (Rs) }\end{array}$ & 3.05 & 5.14 & 5.53 & 5.90 & 6.38 \\
\hline
\end{tabular}


Fig.1 Long run average cost curve

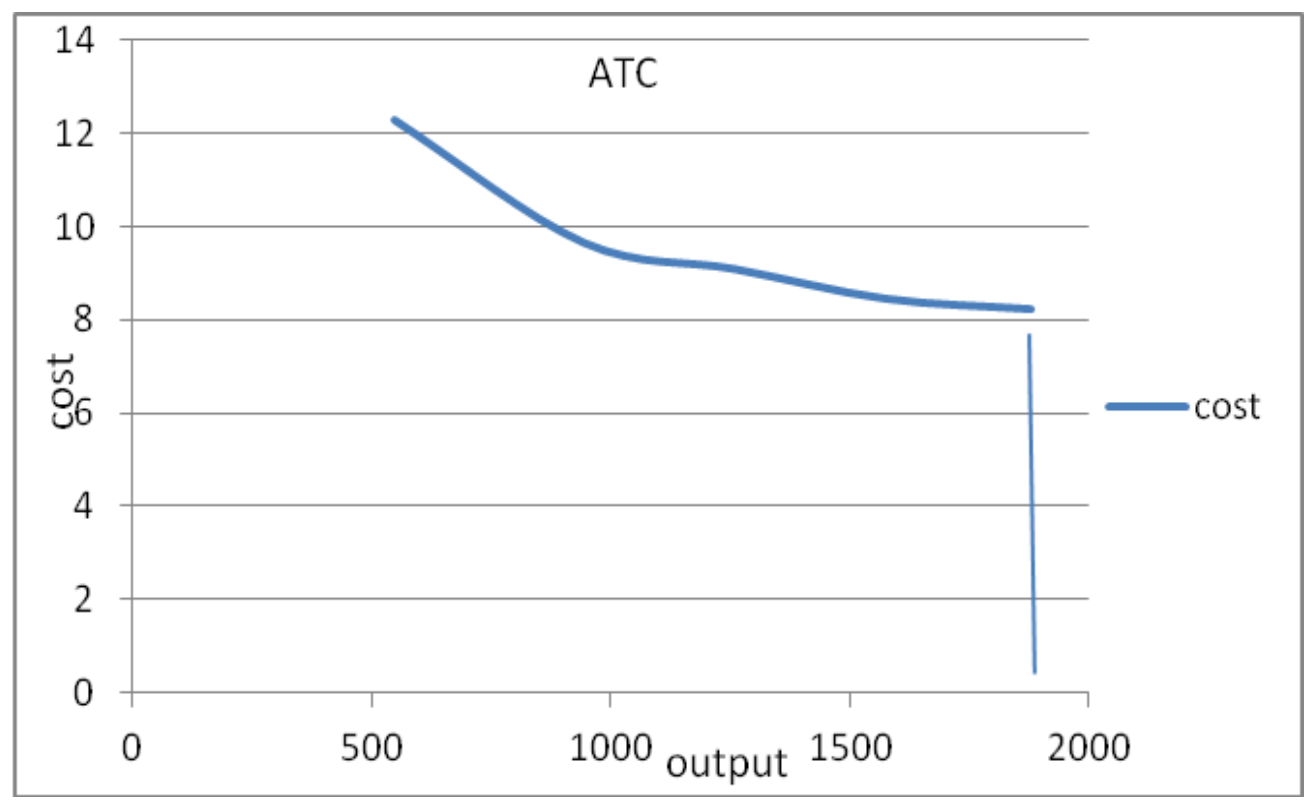

\section{Fixed cost incurred by tapioca processing}

The fixed cost of processing firm in different scale of production is depicted in Table 4. Fixed cost included Salary of the manager, Repairs and maintenance, Duties and taxes, Depreciation, Rental value of land.

Let us look into fixed cost, depreciation was a major component with the share ranging from 72 to 77 percent followed by repairs and maintenance, salary of the manager, rental value of land and duties and taxes. The fixed cost for the smallest firm to be 21 lakh rupees and it was 28.74 lakh rupees for the largest firm. The total fixed cost was found to increase across the scale of production.

\section{Total processing cost of tapioca processing firms}

The total processing cost of the processing firms depicted in the Table 5. The total processing cost was worked by summing annual share of capital, variable cost and fixed cost. The total processing cost $\mathrm{kg}$ of processed product was 12.3 rupees for smallest firm and it decreased across scale of production and the processing cost per $\mathrm{kg}$ was 8.21 rupees for largest firm.

Profit realized in the tapioca processing firms

The profit realized in the processing firms in different scale of production is depicted in the Table 6. The net return realised in the smallest firm was 16.7 lakh rupees and it increased across the scale of processing and it was 120.11 lakh rupees for the largest firm. The profit realised per $\mathrm{kg}$ of the product was 3.05 rupees for the smallest firm while it was 6.38 for the largest firm.

\section{Long run average cost curve}

Long run average cost curve was depicted in the Figure 1. Long run average cost was drawn by taking average processing cost and the output realised for different size of processing units. The optimum size of the industry is decided at the output level of 1881 (above 1701) with the minimum processing cost per $\mathrm{kg}$ was 8.21 rupees. 


\section{Constraints faced by the processors}

The major constraints voiced by the processors are non-availability of quality raw material in adequate quantity, High fluctuation in prices of the raw material, Availability of raw material only for a short period. The next major constraint is the processors felt that high cost of electricity, frequent power cuts and voltage drops were limiting the production activity and even leading to disruption of the production activity itself and high transportation cost is one of the constraint faced by the processors.

The growth of the tapioca processing industries in Salem district of Tamil Nadu will bring large benefits to the people by way of employment and income. The evolving high yielding tapioca variety with minimum cost of production would help ensuring adequate supply of raw materials to the processing industry. The government should give stream lining the power supply at appropriate voltage and subsidising power may help in stabilising the performance of tapioca units. High transportation cost was one of the constraint expressed by processors. Formation of cooperative transport system on the part of all the firms in the industry may be a viable option to reduce the cost of transportation.

\section{References}

Karthick, V., K.Mani and A.Anbarassan., (2013)Mango Pulp Processing Industry in Tamil Nadu-An Economic Analysis, American International Journal of Research in Humanities, Arts and Social Sciences, 2(1), pp. 48-52.

Ruchira shukla, Bhavesh chaudhari, Gayatri joshi, A.K.Leua and Rahul, G.Thakkar., (2015) An Economic Analysis of Mango Pulp Processing in South Gujarat. Indian Journal of agricultural marketing, 29(1).

Toluwase, S. O and K. A. Abdu-raheem., (2013)Costs and returns analysis of cassava production in Ekiti State, Nigeria. Scholarly Journal of Agricultural Science Vol. 3(10), pp. 454-457.

Varalakshmi, K, (2015) Feasibility Analysis of Meat processing plant -Case of medium scale plant for Restructured chicken products. International Journal of Advanced Research, Volume 3, Issue $8,750-763$

Vigneshwara Varmudy., (2014) Cassava Cultivation and Export: Vast Scope in India. Facts for You, pp.22-25.

Website: www.sagoserve.com/profile1.htm, www.fao.org/ag/agp/agpc/gcds/index_e n.html

\section{How to cite this article:}

Kathiravan, V., S. Saranya, K. Sangli Vikram Kumar and David Rajasekar, D. 2017. Economics of Processing of Different Tapioca Based Products in Salem District of Tamil Nadu, India. Int.J.Curr.Microbiol.App.Sci. 6(11): 1613-1619. doi: https://doi.org/10.20546/ijcmas.2017.611.193 